Case Report

\title{
Polypoid Carcinoma of the Oropharynx with Stromal Ossifying Myofibroblastic Proliferation: A Case Report and Literature Review
}

\author{
Marcello Filotico and Alessandro D'Amuri \\ Department of Anatomic Pathology, Fondazione Card. Panico Azienda Ospedaliera, Tricase, Italy \\ Correspondence should be addressed to Marcello Filotico; mfilotico@libero.it
}

Received 6 June 2016; Accepted 15 November 2016

Academic Editor: Akira Mima

Copyright (C) 2016 M. Filotico and A. D’Amuri. This is an open access article distributed under the Creative Commons Attribution License, which permits unrestricted use, distribution, and reproduction in any medium, provided the original work is properly cited.

A 76-year-old man reported a worsening difficulty in swallowing, leading to the inability to eat. Physical examination and CT scan revealed a polypoid mass on the posterior oropharynx and obstructing the oropharyngeal space. Histologically, the surface was ulcerated. In the underlying necrotic rim, there was active granulation tissue, and a proliferation of voluminous, globoid elements with hyperchromatic and irregular nucleus, sometimes arranged in a alveolar aggregate. The core of the lesion contained spindlelike myoid elements in interwoven bundles, with trabeculae of osteoid matrix maturing into calcified bone. Immunohistochemistry documented positivity for cytokeratins, epithelial membrane antigen, and P63 in the globoid elements beneath the necrotic rim; strong and diffuse expression of vimentin, smooth muscle actin, and CD99 and BCL2 in the spindle elements; and complete negativity for cytokeratin 5/6, high molecular weight cytokeratin (clone 34 $\beta \mathrm{E} 12$ ), S100, muscle-specific actin, desmin, CD117, and anaplastic lymphoma kinase. The lesion was morphologically and immunophenotypically classified as a polypoid oropharyngeal carcinoma with ossifying myofibroblastic stromal proliferation.

\section{Introduction}

For many years, the pathologic meaning of polypoid lesions on the oropharyngeal, laryngeal, and esophageal mucosae has been debated. These lesions are characterized by a superficial ulcerated squamous carcinoma, often in situ, associated with a sarcomatoid stroma. For this reason, they are called pseudosarcomas [1]. One of us (MF) has a long interest in this type of lesion $[2,3]$. The peculiar pathologic presentation of such a lesion has led us to return to the subject.

\section{Case}

A 76-year-old Italian man reported a worsening difficulty in swallowing over several months leading to the inability to eat. Physical examination revealed a polypoid mass on the posterior wall of the oropharynx. CT of the head and neck showed that the lesion had a wide base and a diameter of about $3 \mathrm{~cm}$, occupying almost all the oropharynx (Figures 1(a) and 1(b)); foci of calcium deposits were also seen (Figure 1(c)).
The patient underwent surgical resection of the tumor and was then referred for chemotherapy and radiotherapy. His rapidly deteriorating conditions did not allow the full administration of the treatments, and he died five months after diagnosis.

2.1. Histopathological Analysis. The surgical specimen was a $2 \times 1.5 \times 1 \mathrm{~cm}$, voluminous fleshy polypoid fragment, pink, with ulcerated surface. The material was fixed in formalin and embedded in paraffin; it was stained with hematoxylin and eosin and studied by immunohistochemistry.

In the specimen, we distinguished two areas: one peripheral and another deeper. The peripheral area consisted of necrotic inflammatory tissue (Figure 2(a)) on which only short sections of residual squamous surface epithelium were recognizable (Figure 2(b)). Within the necrotic outer layer, a brisk microangiogenesis by granulation tissue is present, which is intermingled groups of plump, spindled, or globoid cells, with hyperchromatic and irregular nuclei, sometimes with atypical 


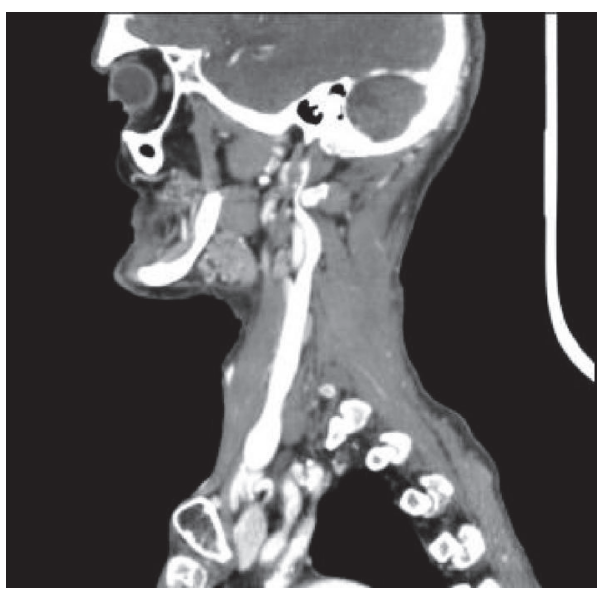

(a)

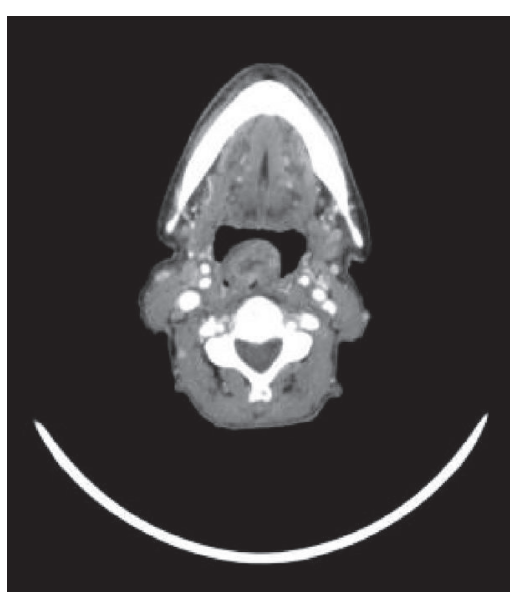

(b)

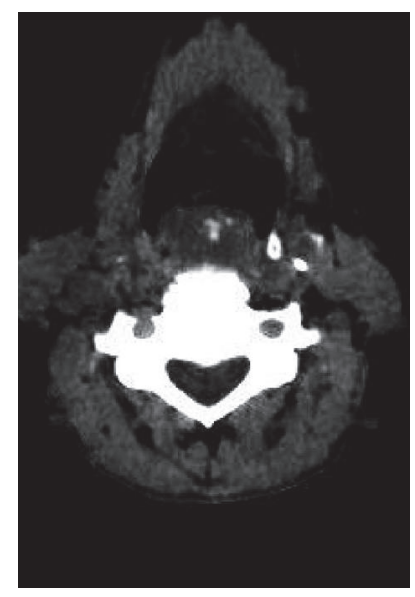

(c)

FIGURE 1: CT scans of the patient. (a) Sagittal view of head and neck. (b, c) Axial views.

mitosis, and aggregates in a pseudoalveolar fashion (Figures $2(\mathrm{c})$ and $2(\mathrm{~d})$ ).

The core of the lesion consisted of a proliferation of spindled, myoid-like elements, assembled in interwoven bundles, with voluminous, oval, hyperchromatic nuclei (Figures 3(a) and $3(\mathrm{~b})$ ). Here, the cytoplasm was abundant and amphophilic, and mitotic activity was fairly lively. In the context of the spindled proliferation, we observed trabeculae of osteoid matrix with some areas of calcified cancellous bone (Figures $3(\mathrm{c})$ and $3(\mathrm{~d}))$. In the spindled core, microangiogenesis was absent.

Immunohistochemical analysis (Table 1) highlighted positivity for cytokeratins (Figure 4(a)), epithelial membrane antigen, and P63, with varying intensity and frequency, in the atypical elements present in the superficial necrotic tissue, but not in the spindled core (Figure 4(b)). The spindled core expressed, with varying intensity and frequency, vimentin (Figure 4(c)), smooth muscle actin (Figure 4(d)), calponin, CD99 (Figure 5(a)), and BCL2 (focal). There was complete negativity for S100, cytokeratin $5 / 6$, high molecular weight cytokeratin (clone $34 \beta \mathrm{el} 2$ ), muscle-specific actin, desmin, CD117, and anaplastic lymphoma kinase (ALK). Staining for $\mathrm{Ki}-67$ revealed a rather high proliferation index $(35 \%)$ in atypical elements expressing cytokeratins (Figure 5(b)). Staining for CD34 indicated rich microangiogenesis in the granulation tissue of the superficial necrotic band, but a paucity of vascular proliferation in the deeper area (Figures 5(c) and 5(d)).

Fluorescence in situ hybridization was used to assess the state of the SYT gene (18q11.2). This work indicated that the gene was not affected by translocation (data not shown).

\section{Discussion}

Since 1957, when Lane [4] first described these peculiar polypoid lesions of the upper aerodigestive tract, the debate about their meaning has not yet been exhausted, despite the remarkable progress in the fields of morphology, immunohistochemistry, and molecular biology that occurred during the
TABLE 1: Immunoreactivity of the neoplasm.

\begin{tabular}{|c|c|c|c|}
\hline \multirow{2}{*}{$\begin{array}{l}\text { Antigen } \\
\text { (antibody clone) }\end{array}$} & \multirow{2}{*}{$\begin{array}{l}\text { Antibody }^{\mathrm{a}} \\
\text { dilution }\end{array}$} & \multicolumn{2}{|c|}{ Immunoreactivity } \\
\hline & & Superficial layer & Core \\
\hline ALK & $1: 25$ & - & - \\
\hline BCL2 & $1: 50$ & - & $+\mathrm{f}$ \\
\hline Calponin & $1: 50$ & - & \pm \\
\hline CD31 & $1: 20$ & $+g t$ & - \\
\hline CD34 & $1: 20$ & $+g t$ & - \\
\hline CD99 & $1: 250$ & - & + \\
\hline CD117 & $1: 400^{\mathrm{b}}$ & - & - \\
\hline CK (clone AE1/AE3) & $1: 50$ & $+\mathrm{f}$ & - \\
\hline CK 5/6 & $1: 50$ & - & - \\
\hline $\begin{array}{l}\text { CKhmw } \\
\text { (clone } 34 \beta \mathrm{E} 12 \text { ) }\end{array}$ & $1: 100$ & - & - \\
\hline Desmin & $1: 50$ & - & - \\
\hline EMA & $1: 50$ & \pm & \\
\hline Muscle-specific actin & $1: 50$ & - & + \\
\hline Ki-67 & $1: 75$ & $35 \%$ positive & $25 \%$ \\
\hline P63 & $1: 75$ & $\pm f$ & \\
\hline S100 & $1: 000^{b}$ & - & - \\
\hline Smooth muscle actin & $1: 50$ & - & + \\
\hline Vimentin & $1: 50$ & - & + \\
\hline
\end{tabular}

${ }^{a}$ All antibodies are from Dako and monoclonals unless otherwise indicated. ${ }^{\mathrm{b}}$ Polyclonal antibody.

CK, cytokeratin; +, positive; -, negative; \pm , positivity observed in $<15 \%$ of cells in the sample; gt, granulation tissue; $\mathrm{f}$, focal

nearly sixty years since the first report [5-7]. The debate essentially concerns the significance of the "sarcomatous" component that makes up the core of these lesions. Some, Lane among them, believe that the granulation tissue, under particular circumstances (carcinoma in situ, ulceration in the mucosa, and squamous epithelium), grows with abnormal 


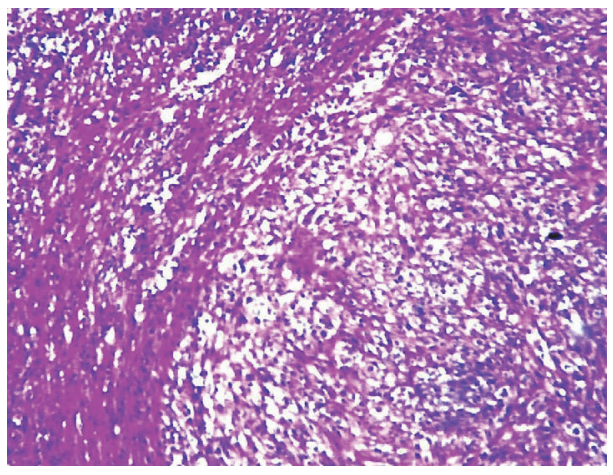

(a)

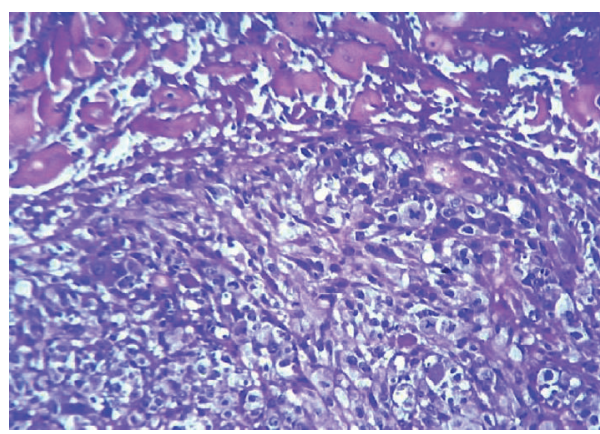

(c)

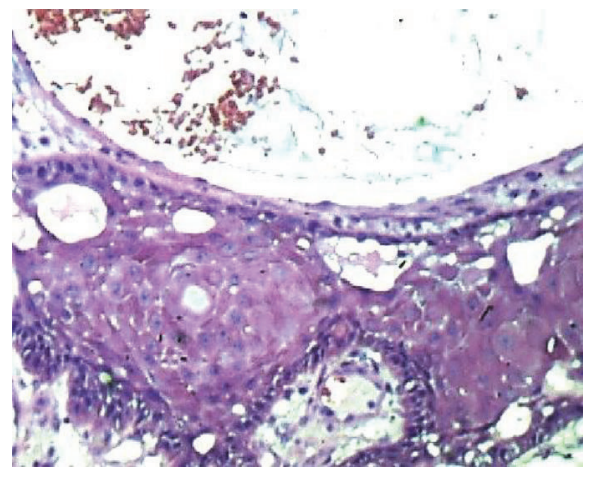

(b)

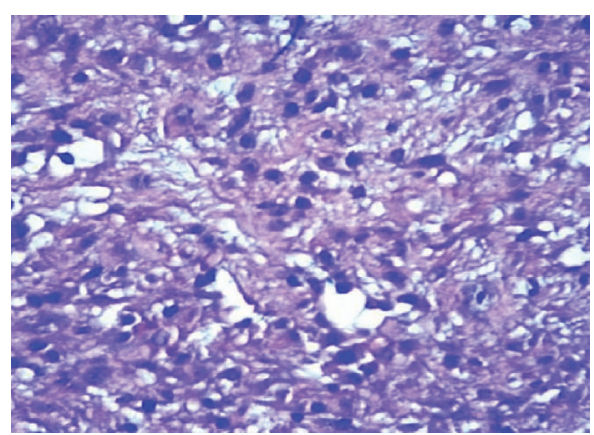

(d)

Figure 2: Peripheral part of the tumor. (a) Necrotic surface of the polypoid neoformation (40x). (b) Hyperplastic residual squamous epithelium (40x). (c) Atypical spindle and globoid elements beneath the necrotic area (100x). (d) Atypical elements in alveolar aggregation $(100 x)$.

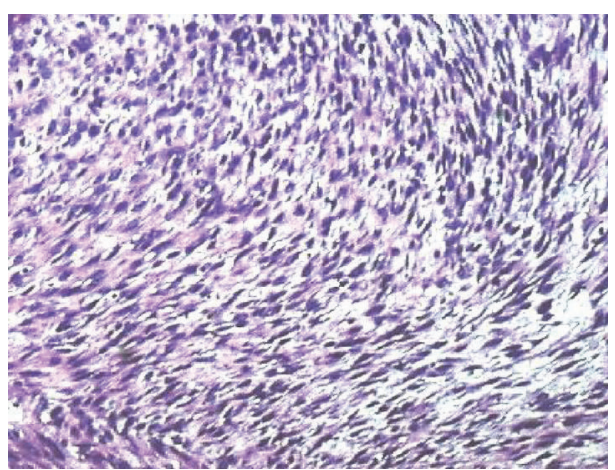

(a)

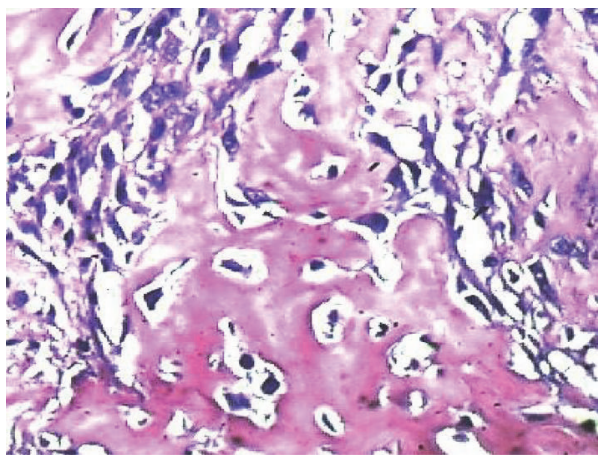

(c)

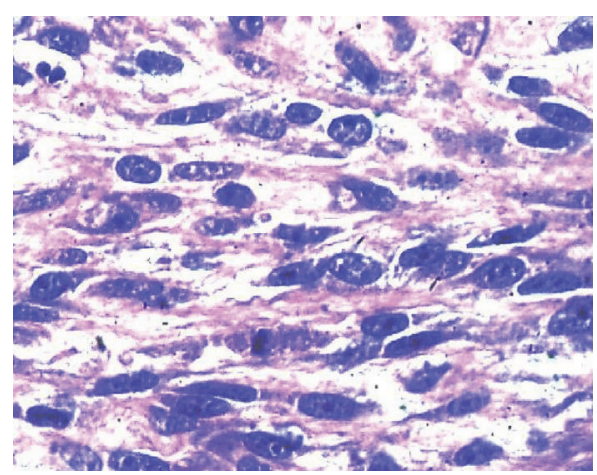

(b)

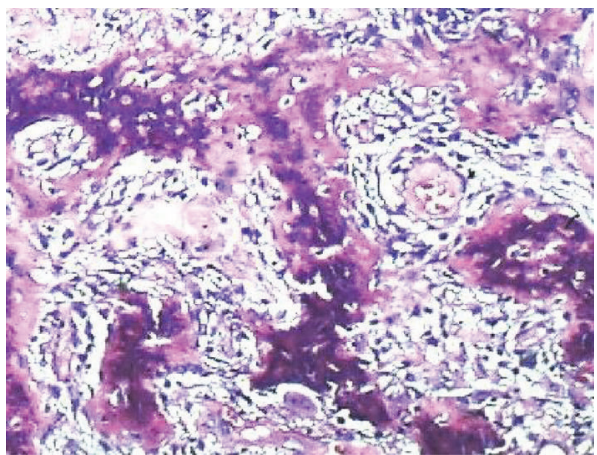

(d)

Figure 3: Core of the tumor. (a) Monomorphic proliferation of spindle elements (40x). (b) Myoid morphology (100x). (c) Osteoid trabeculae. (d) Mature trabecular bone. 


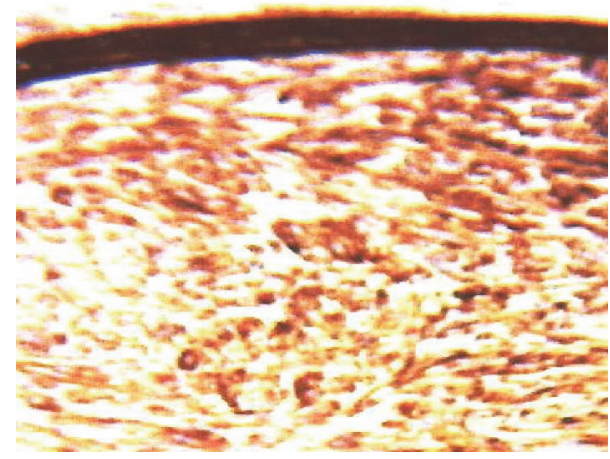

(a)

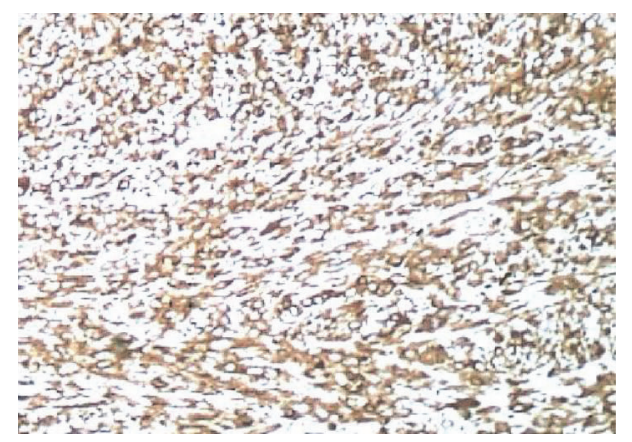

(c)

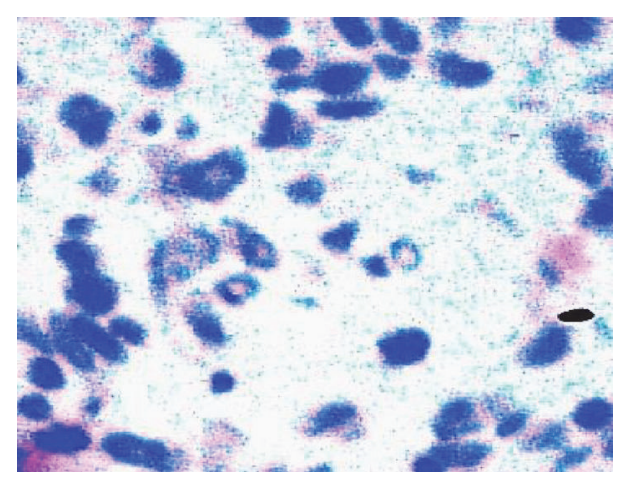

(b)

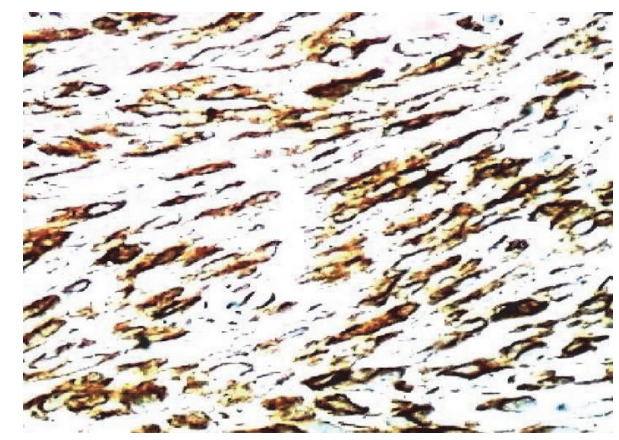

(d)

FIGURE 4: Immunohistochemistry. (a) Intense positivity for cytokeratin (clone AE1-AE3) of atypical elements in subepithelial site (40x). (b) Total negativity for cytokeratin (clone AE1-AE3) in the spindle elements of the core. (c) Vimentin positivity in the spindle component. (d) $\alpha$-Smooth muscle actin positivity.

characteristics, taking on sarcomatoid morphology and polypoid conformation; they call these lesions "pseudosarcomas" $[3,6,8,9]$. Others consider the sarcomatous proliferation epithelial in nature and therefore label the lesions as "sarcomatoid carcinomas" [10-13]. Still others consider these proliferations as the sarcomatous component of a carcinosarcoma [9]. According to the literature, all three of the options are possible $[8,9,11,14]$.

The first option describes a pleomorphic cell morphology of the "sarcomatous" component, associated with an equally pleomorphic immunophenotype indicative of the histiomonocytic proliferation and the microangiogenesis of the granulation tissue (i.e., positivity for vimentin, actin, calponin, desmin, CD31, CD34, and CD68), without expression of epithelial antigens. The second, based on the "sarcomatous" component's expression of cytokeratins (particularly high molecular weight cytokeratin) which is often associated with the expression of mesenchymal antigens like vimentin, focuses on the carcinomatous nature of the proliferationsarcomatoid carcinoma. The third, in addition to considering the carcinomatous proliferation, emphasizes the unmistakable characteristics of a mesenchymal malignancy with sometimes heterologous characteristics (resembling rhabdo-, leiomyo-, and chondroosteosarcomas) with a conforming immunophenotypic profile.

The particular features in this case are (1) polypoid conformation, (2) ulceration, (3) evidence of an epithelial neoplasm in the context of necrotic tissue, well highlighted by the immunohistochemical analysis, (4) the core, consisting of a monomorphic proliferation of spindled, myoid-like elements, between which there was focal deposition of osteoid material and mature cancellous bone, and (5) strong positivity of the spindled component for vimentin, $\alpha$-smooth muscle actin, CD99, and BCL2.

This case is not a typical Lane's pseudosarcoma, insofar as the sarcomatoid component lacks morphologic and immunophenotypic features characteristic of granulation tissue, which are present, on the other hand, in the peripheral necrotic tissue. This case does not fulfill the immunophenotypic characteristics of a sarcomatoid carcinoma because the sarcomatoid component does not express epithelial antigens. The possibility of a monophasic synovial sarcoma of the oropharynx [15], considering the positivity for cytokeratins, CD99, and BCL2, or of its variant ossificans form [16, 17], is discarded by the absence of an SYT translocation. The presence of contractile filaments, throughout most of the bulk of the tumor, provides evidence for the myofibroblastic nature of the proliferation. The bone component is the result of the maturation of an osteoid matrix which originated between the spindle cells (Figure 3(c)) leading to the formation of mature trabecular bone (Figure 3(d)). This type of direct ossification without cartilaginous precursors is reminiscent of myositis ossificans, in which the cellular component is represented by myofibroblasts. 


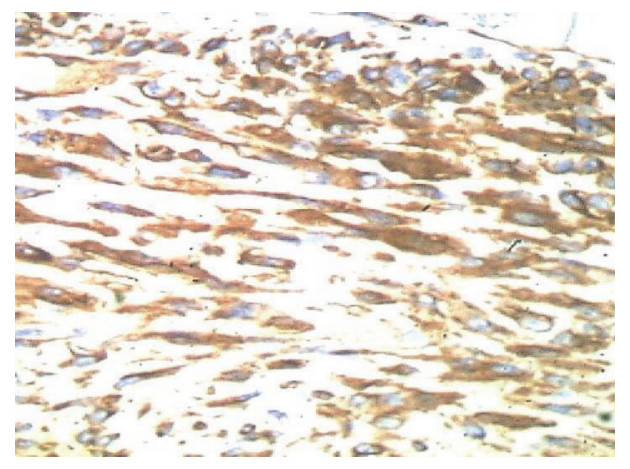

(a)

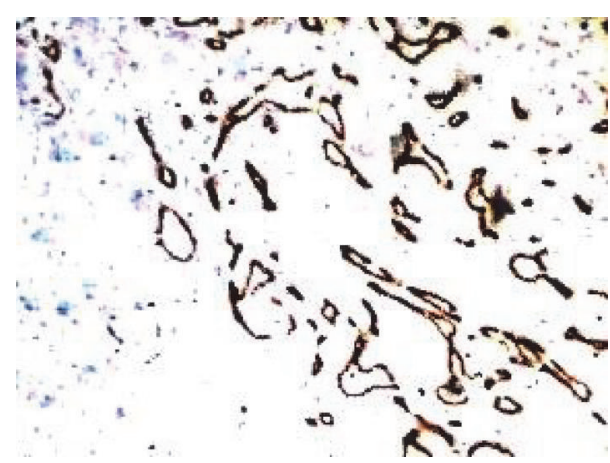

(c)

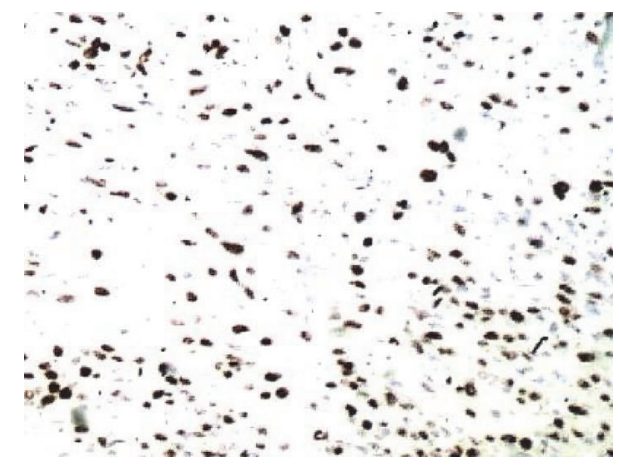

(b)

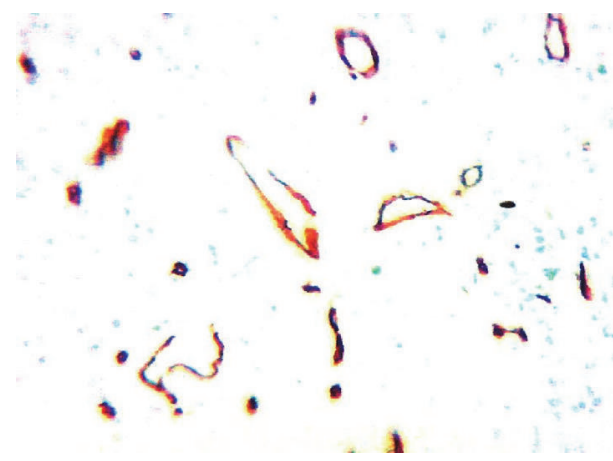

(d)

Figure 5: Immunohistochemistry. (a) Intense and diffuse positivity for CD99 in the spindle elements. (b) Ki-67 positivity in the spindle elements. (c) Positivity for CD34 in the superficial granulation tissue. (d) Positivity for CD34 in the core.

In summary, the tumor in question has only some of the characteristics of the most common polypoid malignancies of the upper aerodigestive tract, variously labeled as pseudosarcomas, sarcomatoid carcinomas, and carcinosarcomas. A carcinomatous component was demonstrated morphologically and immunophenotypically, in the superficial necrotic tissue (Figures 2(c), 2(d), and 4(a)). The core of the lesion does not have the characteristics of atypical granulation tissue or those of a sarcomatoid carcinoma, but rather that of a monomorphic proliferation of myofibroblasts.

This morphologic and immunophenotypic profile may be compared to that of a group of lesions that goes under the umbrella definition of "pseudosarcomatous myofibroblastic proliferations" (PMPs) [18-22]. PMPs are similar to nodular fasciitis in its various expressions (proliferative fasciitis, proliferative myositis, and ossificans) $[19,21]$ and from time to time are labeled under various designations such as visceral fasciitis, pseudosarcomatous fibromyxoid tumor [19], spindle cell pseudomalignant proliferation, postoperative spindle cell nodule [23], and inflammatory pseudotumor [18]. These lesions most often occur in the genitourinary system (bladder, prostate, ureter, vagina, and vulva) [24-26] but can occasionally arise in the gastrointestinal tract $[27,28]$ or in the organs of the upper aerodigestive tract (pharynx, larynx, nasal cavities, and mouth) [29,30]. They should be clearly distinguished from the inflammatory myofibroblastic tumor (IMT) [31, 32], and for this reason the confusing adjective inflammatory should be avoided in their description.
Unlike nodular fasciitis, where there are clonal aberrations in different areas of the genome [33-35], in PMP these have not been reported. In $50 \%$ of the cases, the lesions are positive to ALK, which usually does not correspond to any ALK rearrangements detectable with FISH. When this occurs, these cases are classified as IMT [21].

The positivity for CD99 and BCL2 in this case suggests that the tumor is quite different from classic myofibroblastic proliferations, such as nodular fasciitis, fibromatosis, and dermatofibroma, as well as from benign and malignant smooth muscle proliferations, which are all uniformly negative for these antigens. However, with current knowledge, we are unable to define the lesion, just as we are unable to determine whether the proliferation is neoplastic or merely reactive.

The analysis of this case shows that the "sarcomatoid" proliferation associated with the polypoid carcinoma of the high aerodigestive tract, in addition to a reactive (Lane's tumor) or neoplastic epithelial (sarcomatoid carcinoma) process, may be due to other proliferative conditions, which in this case has the morphological and immunophenotypic characteristics of a myofibroblastic proliferation. To date, lesions of this type associated with a polypoid carcinoma of the upper aerodigestive tract have not been reported in the literature.

\section{Competing Interests}

The authors declare that they have no conflict of interests with the contents of this report. 


\section{Acknowledgments}

The authors thank Dr. Paola Collini from Istituto Nazionale Tumori in Milan, Italy, for her kind cooperation in the interpretation of this case and Dr. Valerie Matarese for having made editorial suggestions.

\section{References}

[1] A. E. Rosenberg, "Pseudosarcomas of soft tissue," Archives of Pathology and Laboratory Medicine, vol. 132, no. 4, pp. 579-586, 2008.

[2] M. Filotico and M. Trabucco, "Contribution to the knowledge of so-called 'pseudosarcoma' associated with laryngeal carcinoma," Tumori, vol. 52, no. 4, pp. 295-301, 1966.

[3] M. Filotico and R. Filotico, "Lane's type pseudosarcoma of glans penis. A case report," Pathologica, vol. 108, pp. 1-6, 2016.

[4] N. Lane, "Pseudosarcoma (polypoid sarcoma-like masses) associated with squamous-cell carcinoma of the mouth, fauces, and larynx; report of ten cases," Cancer, vol. 10, no. 1, pp. 19-41, 1957.

[5] D. C. Baker Jr., "Pseudosarcoma of the pharynx and larynx," The Annals of Otology, Rhinology, and Laryngology, vol. 68, no. 2, pp. 471-477, 1959.

[6] J. G. Batsakis, "Pseudosarcoma' of the mucous membranes in the head and neck," Journal of Laryngology and Otology, vol. 95, no. 3, pp. 311-316, 1981.

[7] O. Kleinsasser and H. Glanz, "Sarcomalike patterns in laryngeal carcinoma (pseudosarcoma, carcinosarcoma, spindle-cellcarcinoma, pleomorphic carcinoma)," Laryngologie Rhinologie Otologie, vol. 57, no. 3, pp. 225-234, 1978.

[8] D. Ophir, G. Marshak, and B. Czernobilsky, "Distinctive immunohistochemical labeling of epithelial and mesenchymal elements in laryngeal pseudosarcoma," Laryngoscope, vol. 97, no. 4, pp. 490-494, 1987.

[9] X. Zhang, "The morphological and immunohistochemical study of esophageal pseudosarcomatous and carcinosarcomas -report of 10 cases," Zhonghua Zhong Liu Za Zhi, vol. 15, no. 5, pp. 355-357, 1993.

[10] G. W. Willis, "Metastatic metaplastic carcinoma from a pseudosarcoma (Lane tumor) of the mouth," Southern Medical Journal, vol. 70, no. 12, pp. 1467-1468, 1977.

[11] F. P. Kuhajda, T. T. Sun, and G. Mendelsohn, "Polypoid squamous carcinoma of the esophagus. A case report with immunostaining for keratin," American Journal of Surgical Pathology, vol. 7, no. 5, pp. 495-499, 1983.

[12] A. A. Gal, S. E. Martin, J. A. Kernen, and M. J. Patterson, "Esophageal carcinoma with prominent spindle cells," Cancer, vol. 60, no. 9, pp. 2244-2250, 1987.

[13] S. Viswanathan, K. Rahman, S. Pallavi et al., "Sarcomatoid (Spindle Cell) carcinoma of the head and neck mucosal region: a clinicopathologic review of 103 cases from a Tertiary Referral Cancer Centre," Head and Neck Pathology, vol. 4, no. 4, pp. 265275, 2010.

[14] A. Sarma, R. Das, J. D. Sharma, and A. C. Kataki, "Spindle Cell Carcinoma of the Head and Neck: a clinicopathological and Immunohistochemical Study of 40 Cases," Journal of Cancer Therapy, vol. 3, no. 6, pp. 1055-1059, 2012.

[15] N. P. B. Kadapa, L. S. Reddy, R. Swamy, Kumuda, M. V. V. Reddy, and L. M. C. S. Rao, "Synovial sarcoma oropharynx-a case report and review of literature," Indian Journal of Surgical Oncology, vol. 5, no. 1, pp. 75-77, 2014.
[16] S. Milchgrub, L. Ghandur-Mnaymneh, H. D. Dorfman, and J. Albores-Saavedra, "Synovial sarcoma with extensive osteoid and bone formation," American Journal of Surgical Pathology, vol. 17, no. 4, pp. 357-363, 1993.

[17] M. Hisaoka, A. Matsuyama, S. Shimajiri et al., "Ossifying synovial sarcoma," Pathology-Research and Practice, vol. 205, no. 3, pp. 195-198, 2009.

[18] G. L. Stark, R. Feddersen, B. A. Lowe, C. T. Benson, W. Black, and T. A. Borden, "Inflammatory pseudotumor (pseudosarcoma) of the bladder," Journal of Urology, vol. 141, no. 3, pp. 610$612,1989$.

[19] J. Y. Ro, A. K. El-Naggar, M. B. Amin, A. A. Sahin, N. G. Ordonez, and A. G. Ayala, "Pseudosarcomatous fibromyxoid tumor of the urinary bladder and prostate: immunohistochemical, ultrastructural, and DNA flow cytometric analyses of nine cases," Human Pathology, vol. 24, no. 11, pp. 1203-1210, 1993.

[20] K. Sato, Y. Oda, Y. Ueda, and S. Katsuda, "Fasciitis ossificans of the breast," Pathology Research and Practice, vol. 203, no. 10, pp. 737-739, 2007.

[21] J. L. Hornick, Practical Soft Tissue Pathology: A Diagnostic Approach, Saunders, Philadelphia, Pa, USA, 2013.

[22] L. R. Harik, C. Merino, J.-M. Coindre, M. B. Amin, F. Pedeutour, and S. W. Weiss, "Pseudosarcomatous myofibroblastic proliferations of the bladder: A Clinicopathologic Study of 42 Cases," American Journal of Surgical Pathology, vol. 30, no. 7, pp. 787794, 2006.

[23] T. G. Carlà, R. Filotico, and M. V. Filotico, "Postoperative spindle cell nodules (PSCN) resembling sarcomas: an atypical granulation tissue or atypical pyogenic granuloma with exuberant myofibroblasts component?" Pathologica, vol. 82, no. 1079, pp. 279-286, 1990.

[24] J. Albores-Saavedra, J. C. Manivel, H. Essenfeld et al., "Pseudosarcomatous myofibroblastic proliferations in the urinary bladder of children," Cancer, vol. 66, no. 6, pp. 1234-1241, 1990.

[25] K. Chandramouleeswari, S. Anita, and B. Shivali, "Pseudosarcomatous myofibroblastic tumour of the urinary bladder: a case report," Journal of Clinical and Diagnostic Research, vol. 6, no. 8, pp. 1422-1424, 2012.

[26] S. Alquati, F. A. Gira, V. Bartoli, S. Contini, and D. Corradi, "Low-grade myofibroblastic proliferations of the urinary bladder," Archives of Pathology and Laboratory Medicine, vol. 137, no. 8, pp. 1117-1128, 2013.

[27] L. Guerrero Puente, M. Muñoz García-Borruel, P. Barrera Baena, and M. de la Mata García, "Inflammatory pseudotumor of the liver: a propos of a case," Gastroenterologia y Hepatologia, vol. 3, pp. 150-158, 2015.

[28] R. Alloni, G. Ancona, I. Gallo, A. Crescenzi, and R. Coppola, "Melena as presentation of primary small intestine inflammatory myofibroblastic tumor in an adult woman. A case report," Annali Italiani di Chirurgia, vol. 29, article 86, 2015.

[29] H. Yokoi, T. Yazawa, Y. Matsumoto et al., "An inflammatory pseudotumor arising from pterygopalatine fossa with invasion to the maxillary sinus and orbital cavity," Case Reports in Otolaryngology, vol. 2015, Article ID 950823, 5 pages, 2015.

[30] M. Tanţău, L. Ciobanu, T. Zaharie, G. Mester, and A. Tanţău, "Giant inflammatory pseudotumor of the larynx treated endoscopically by a gastroenterologist using submucosal dissection," Endoscopy, vol. 47, supplement 1, pp. E352-E353, 2015.

[31] B. C. Gleason and J. L. Hornick, "Inflammatory myofibroblastic tumours: where are we now?" Journal of Clinical Pathology, vol. 61, no. 4, pp. 428-437, 2008. 
[32] T. Zhang, Y. Yuan, C. Ren et al., "Recurrent inflammatory myofibroblastic tumor of the inguinal region: a case report and review of the literature," Oncology Letters, vol. 10, no. 2, pp. 675680, 2015.

[33] J. R. Sawyer, G. Sammartino, G. F. Baker, and J. M. Bell, "Clonal chromosome aberrations in a case of nodular fasciitis," Cancer Genetics and Cytogenetics, vol. 76, no. 2, pp. 154-156, 1994.

[34] V. M. Weibolt, C. J. Buresh, C. A. Roberts et al., "Involvement of 3q21 in nodular fasciitis," Cancer Genetics and Cytogenetics, vol. 106, no. 2, pp. 177-179, 1998.

[35] M. R. Erickson-Johnson, M. M. Chou, B. R. Evers et al., "Nodular fasciitis: a novel model of transient neoplasia induced by MYH9-USP6 gene fusion," Laboratory Investigation, vol. 91, no. 10, pp. 1427-1433, 2011. 


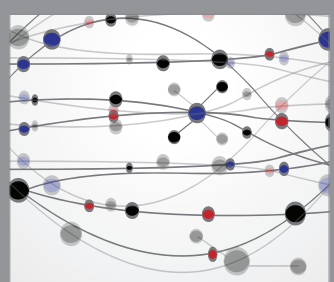

The Scientific World Journal
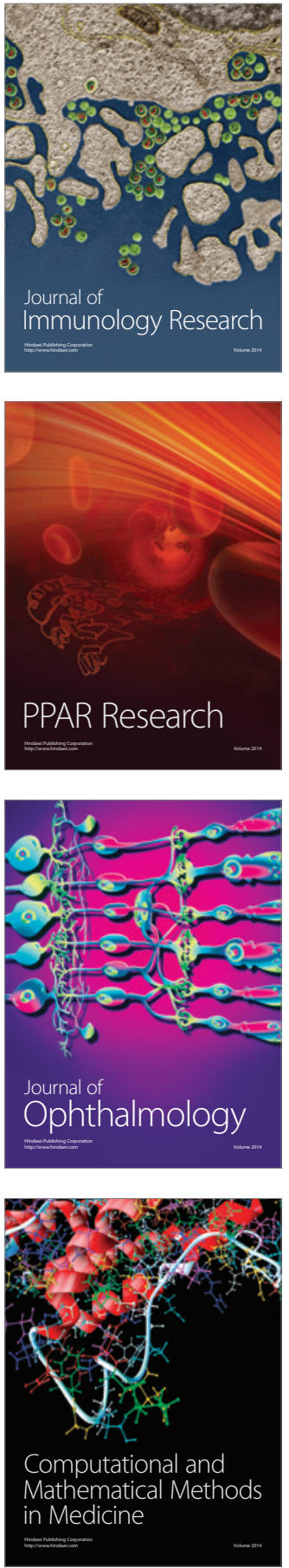

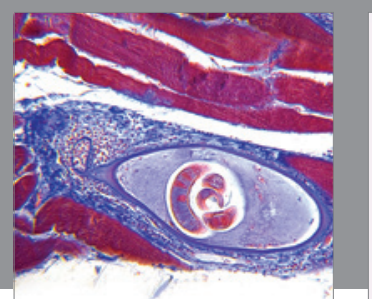

Gastroenterology Research and Practice

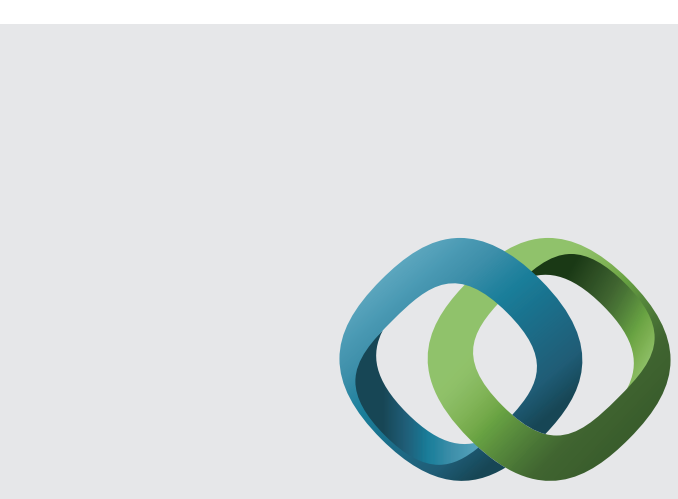

\section{Hindawi}

Submit your manuscripts at

http://www.hindawi.com
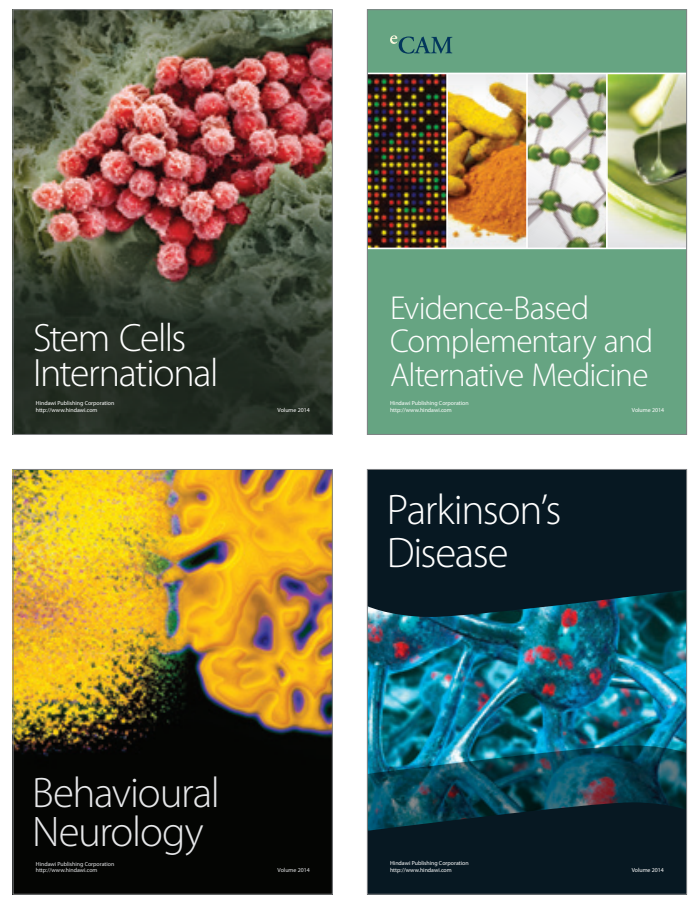
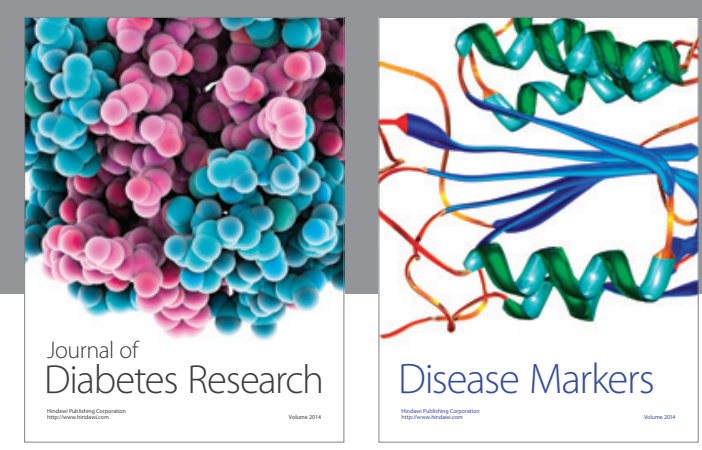

Disease Markers
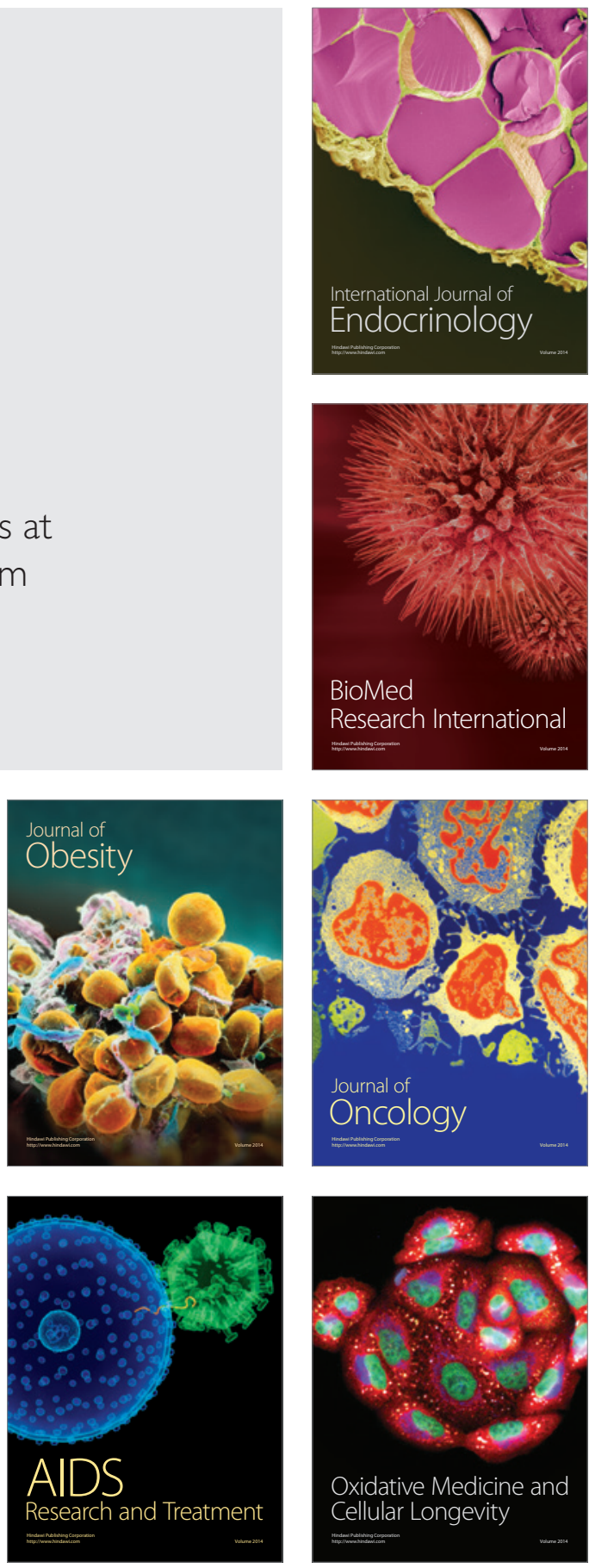